Currículo sem Fronteiras, v. 19, n. 3, p. 975-991, set./dez. 2019

\title{
DISCURSOS SOBRE AS TIC NA IBEROAMÉRICA: tentativas de controle
}

\author{
Lívia Moura Cardoso de Bastos Farias \\ Universidade do Estado do Rio de Janeiro - UERJ \\ Rosanne Evangelista Dias \\ Universidade do Estado do Rio de Janeiro - UERJ
}

\begin{abstract}
Resumo
Podem as Tecnologias da Informação e Comunicação (TIC) forjadas para as políticas de currículo virem a ser associadas a movimentos educacionais de perfil conservador? Tal questão parece ser desafiadora a certo consenso que atribui exclusivamente sentidos arrojados e progressistas ao advento das TIC na educação e merece ser problematizada. Neste artigo, interpretamos os sentidos que vêm sendo produzidos nas políticas de currículo envolvendo as TIC para as escolas e como seus discursos vêm significando, nos textos políticos da Ibero-América, a docência e a aprendizagem. Selecionamos na análise textos políticos produzidos no período de 2008 a 2016 pela UNESCO e a OEI para interpretar como eles vêm disseminando discursos sobre a inexorabilidade das TIC em um viés conservador que visa destacar o discurso da sociedade do conhecimento na tentativa do controle docente e discente e nos resultados via processos de avaliação centralizada.
\end{abstract}

Palavras-chave: Políticas de currículo; TIC; Ibero-América; Discursos conservadores.

\begin{abstract}
Can Information and Communication Technologies (ICT) forged for curriculum policies be associated with conservative educational movements? This question seems to be challenging to some consensus that attributes exclusively bold and progressive meanings to the advent of ICT in education deserves to be problematized. In this article, we interpret the meanings that have been produced in curriculum policies involving ICTs for schools and how their discourses have meant teaching and learning in Ibero-American political texts. We selected in the analysis political texts produced between 2008 and 2016 by UNESCO and OEI to interpret how they have been spreading discourses about the inexorability of ICT in a conservative bias that aims to highlight the discourse of the knowledge society in the attempt of teacher and student control. and results via centralized evaluation processes.
\end{abstract}

Key-word: Curriculum policies; TIC; Ibero-America; Conservative discourse.

ISSN 1645-1384 (online) www.curriculosemfronteiras.org 


\section{Introdução}

O contexto que envolve a discussão do objeto deste artigo é marcado pela intensificação da produção curricular sobre o uso das Tecnologias de Informação e Comunicação (TIC) no Brasil e no mundo. Essa análise se insere no cenário de discussões sobre a introdução do uso de tais artefatos nas práticas pedagógicas, no âmbito das políticas de currículo públicas no cenário Ibero-americano. Neste artigo, resultado de tese de doutorado em educação ${ }^{1}$, nos sentimos provocadas pela seguinte questão: podem as Tecnologias da Informação e Comunicação (TIC) forjadas para as políticas de currículo virem a ser associadas a movimentos educacionais de perfil conservador? Podem as TIC vir a contribuir no contexto de produção de políticas de currículo para a padronização que tenham como finalidade supostos modelos de aprendizagem, perfis docentes?

Na tentativa de vir a problematizar essas questões, focalizamos os discursos produzidos na Ibero-américa sobre as TIC nas escolas e nos processos educativos. Selecionamos nesta análise textos políticos que pretendem influenciar políticas de currículo para a região. Alguns dos textos formulados por lideranças da comunidade de conhecimento sobre TIC e outros representantes de Estado-nação da região para estabelecer e regular metas das políticas de currículo. Dentre os textos selecionados para a análise dos discursos, destacamos: Los desafíos de las TIC para el cambio educativo (2009); Metas Educativas 2021 - La Educación que Queremos para la Generación de los Bicentenarios (2010a); “Metas Educativas 2021 Documento Final” (2010b); "Los desafíos de las TIC para el cambio educativo” (2011); “A integração das TIC na escola: Indicadores qualitativos e metodologia de pesquisa” (2013); "Padrões de competência em TIC para professores: UNESCO” (2008); “O impacto das TIC na educação: O desenvolvimento de competências em TIC para a educação na formação de docentes na América Latina” (2010) e "Experiências Avaliativas de Tecnologias Digitais na Educação” (2016). Nesta investigação, trabalhamos com registros pós-estruturais a partir dos quais compreendemos que diferentes discursos estão em disputa sobre os sentidos do que é a escola, a docência, a aprendizagem, entre outras questões. Defendemos que há em curso um projeto educacional ligado cada vez mais a interesses conservadores. Um projeto que ganha mais visibilidade em arenas de disputa da política de currículo nos últimos anos em diversos países e no Brasil.

O protagonismo das TIC não escapa aos estudos curriculares, pois cada vez mais se discute o papel das tecnologias nos processos de ensino e aprendizagem. Nos documentos curriculares produzidos no âmbito da Ibero-América, diferentes metas são discutidas em relação aos usos das TIC. São diferentes objetivos projetados em um aluno que ao final do processo educativo estaria preparado para viver e trabalhar na "Sociedade do Conhecimento". No trecho extraído do prefácio do texto "Padrões de competência em TIC para os professores”, produzido pela UNESCO, podemos observar uma projeção identitária deste sujeito.

Para viver, aprender e trabalhar bem em uma sociedade cada vez mais complexa, rica em informação e baseada em conhecimento, os alunos e professores devem 
usar a tecnologia de forma efetiva, pois em um ambiente educacional qualificado, a tecnologia pode permitir que os alunos se tornem: usuários qualificados das tecnologias da informação; pessoas que buscam, analisam e avaliam a informação; solucionadores de problemas e tomadores de decisões; usuários criativos e efetivos de ferramentas de produtividade; comunicadores, colaboradores, editores e produtores; cidadãos informados, responsáveis e que oferecem contribuições. (UNESCO, 2008, p. 01)

Seria então um sujeito informado, responsável, tomador de decisão, entre outras características aquele ideal para a sociedade em que vivemos de acordo com os textos políticos analisados. Aqui cabe trabalharmos com a concepção de saber pós-moderno proposta por Jean-François Lyotard em sua obra “A condição Pós-Moderna” (2011). Para o autor, as transformações tecnológicas têm impacto na concepção do que é o saber na contemporaneidade na medida em que, a partir de 1950, o saber muda de estatuto dentro de um contexto pós-industrial. O saber "não teria mais seu fim em si mesmo como realização da ideia ou como emancipação dos homens” (LYOTARD, 2011, p. 91), mas seria um saber como força de produção e elemento econômico. O que passaria a ser importante nesta nova sociedade não é a sua capacidade de "produzir conhecimento", mas sim a potencialidade deste saber em melhorar a performance e o desempenho dos sujeitos dentro do que ele chama de sistema social.

Pretendemos neste artigo focalizar os discursos produzidos na Ibero-América sobre as TIC nas escolas e nos processos educativos entendendo que os mesmos circulam, constituem políticas e sedimentam sentidos sobre as tecnologias. Trabalhamos com registros pósestruturais com os quais compreendemos que diferentes discursos estão em disputa sobre o que é escola, qualidade da educação, formação docente e sobre as próprias TIC. Buscamos refletir sobre as formas com as quais a tecnologia também é usada para o fortalecimento do conservadorismo através do currículo a partir de questões como o controle de identidade docente e discente, controle de resultados via processos de avaliação centralizada e culpabilização docente.

\section{Tecnologia, o currículo e o controle}

A internet aparece como uma das ferramentas tecnológicas centrais na atualidade e o seu alcance foi potencializado com o desenvolvimento de outros artefatos tecnológicos que permitem e alargam o seu uso. Com isso, queremos indicar que não há uma equivalência entre tecnologia e internet, mas sim que a última é uma forma de tecnologia. Contudo, o que podemos perceber nas últimas décadas é a construção de uma hegemonia da informática dentro do desenvolvimento tecnológico da nossa sociedade.

Tal relevância talvez se dê menos pelos artefatos produzidos e seus impactos e mais pela velocidade de criação de novas tecnologias que transformam muito rapidamente a realidade, as técnicas e as máquinas. Podemos inferir que anteriormente as mudanças não foram tão 
velozes como agora. As grandes transformações ocorridas a partir da aplicação das ferramentas tecnológicas sempre existiram, assim foi com a invenção da roda, da máquina a vapor e da eletricidade, que mudaram as formas de organização das sociedades, mas com um espaço de tempo mais lento entre as mudanças. Hoje, o desenvolvimento tecnológico impacta por sua velocidade de transformação, principalmente quando paramos para pensar que foi apenas há vinte anos que a internet começou a ser utilizada pelo grande público.

O uso da internet móvel possibilitou a conexão prolongada, permitindo que as pessoas fiquem mais tempo online. Assim, potencializou-se os usos das redes sociais. Para a autora Raquel Recuero (2009) rede social é um conjunto de dois elementos: atores e suas conexões. Ainda de acordo com a autora, as redes são muito dinâmicas e estão em constante transformação. A partir das redes, os atores estão interconectados e vão criando formas novas de sociabilização e compartilhamento de conteúdo. Na atualidade, mudanças na vida social e do trabalho de um sujeito são também compartilhadas nas redes. Boa parte das informações são compartilhadas nesses espaços, pessoas expressam a sua opinião sem controle de conteúdo e isso tem transformado as formas de marketing, de relacionamentos e de fazer política.

Nos últimos anos temos observado o crescimento do uso da internet e das redes sociais no que podemos chamar de novas formas de fazer política quando apropriadas e utilizadas de diferentes formas por diferentes grupos defendendo diversos interesses. Kellner (2004) aponta para "um potencial utópico nas novas tecnologias” (p.199) ao situar aspectos que vão desde as possibilidades de permitirem o maior acesso a informações e conhecimentos a diversos problemas e limitações envolvendo "usos desumanizadores, exploradores e opressivos das novas tecnologias nos locais de trabalho, na escola, na esfera pública e na vida cotidiana” (p.202). Se Kellner destaca experiências em que as TIC teve um papel fundamental na ação e propagação de ideias de movimentos sociais progressistas como Exército Zapatista ${ }^{2}$, também podemos citar o uso das redes sociais, por exemplo, como estratégias de campanha eleitoral, como ocorrido nos EUA em 2016 e no Brasil em 2018, quando através de controle de dados e algoritmos estrategistas políticos circularam as chamadas "fake news" que tiveram bastante impacto nos resultados e fortaleceram a atual onda de conservadorismo no Brasil e no mundo.

Tais ferramentas têm sido utilizadas em favor de um discurso conservador que tem atingido diretamente a escola. Movimentos como a Escola sem Partido, o questionamento da chamada "ideologia de gênero", o esvaziamento do discurso científico, o corte de verbas da área da Educação é reflexos desse processo. Interesses do Estado estão conjugados com os interesses privados em relação ao movimento do controle da educação.

O que analisamos nos discursos sobre as TIC são projeções em relação a um determinado sujeito construído através da educação. Esta última seria então entendida como a "condição de uma identidade necessária para o funcionamento harmônico de uma dada sociedade” (CUNHA, 2016, p. 115). Tal crença está relacionada a um discurso que tem por objetivo pensar a sociedade como uma totalidade, uma estrutura fechada onde as peças, se preparadas corretamente, conseguem entrar em harmonia. Nesse movimento, muitos grupos passam a 
projetar, através da escola, a constituição de um sujeito menos plural, estático, mais conservador.

\section{Pensando o controle a partir da Teoria do Discurso}

Nos discursos sobre a inserção das TIC nas práticas escolares e de ensino tem ganhado cada vez mais ressonância aquele que visa projetar essas identidades a priori. O aluno ideal deve ser aquele que está preparado para o mercado de trabalho transformado pelas tecnologias, que saiba utilizar as tecnologias em favor do desenvolvimento de um empreendedorismo, que tenha autonomia, que seja criativo, dentre tantas outras adjetivações e qualificações. Contudo, defendemos que essa projeção é uma tentativa ilusória de construir identidades. Uma tentativa ilusória de controlar aquilo que não pode ser controlado. Como afirmam Lopes e Borges:

No registro teórico pós-fundacional, esse projeto identitário é impossível, porque se mostra impossível conceber identidades plenas. Mesmo quando nomeamos identidades formadas, quando tentamos estabilizar seus sentidos e organizar processos para garantir sua formação, essas identidades nos escapam. (2015, p. 496)

No registro pós-estrutural e pós-fundacional, pensar identidades previamente construídas não se constitui como uma possibilidade. Isto porque entendemos, a partir da Teoria do Discurso, que as subjetivações são forjadas (sempre de maneira incompleta e contingente) através das próprias lutas por significação (LACLAU; MOUFFE, 2015). Tal sujeito não existiria a priori da própria luta política. "O sujeito - entendido como subjetivação - é um projeto inconcluso, um significante circulando a depender de uma significação sempre adiada.” (LOPES, 2013, p.8).

Trabalhamos com a compreensão de um currículo que não é estático. Os sentidos do que se entende por currículo são pretensões de verdade, que buscam se tornar hegemônicas na luta política. Diferentes discursos circulantes favorecem certas visões sobre o que é a educação que, na lógica da busca por uma estabilidade, por vezes, se naturalizam como verdades. Vale lembrar que, a partir dessa perspectiva, tudo sempre pode ser de outra maneira.

No registro pós-estrutural a compreensão radical da linguagem, das práticas sociais, da discursividade tem-se em tela um sem número de tentativas de significações por meio das quais diferentes forças disputam a significação de determinados sentidos sempre contingentes. Desse modo, a TD, de Ernesto Laclau, pode contribuir no que diz respeito aos processos de significações sempre parciais e tornam-se potentes para a interpretação de políticas de currículo que se forjam em processos de luta em terreno indecidível. Para o autor, o universal não passa de particulares que alcançaram o caráter universal, não dissociando 
assim tais dimensões. Posto isso, a TD opera com a categoria de discurso considerando que ela envolve toda e qualquer prática discursiva (LACLAU, 1990).

O discurso compreende uma totalidade estruturada resultante de uma prática articulatória que não se constitui por qualquer necessidade e sim pela contingência. A fixação dos sentidos é sempre incompleta e contingente. Existem fixações provisórias que "fecham" significados que tornam possível a própria comunicação. Isto advém do entendimento de uma estrutura aberta em contraposição à estrutura fechada defendida pelo estruturalismo. Tal abertura permite que articulações discursivas entrem em curso.

Buscando analisar as contingências na produção dos discursos sobre TIC no âmbito ibero-americano, levamos em consideração a possibilidade de des-sedimentação dos sentidos produzidos e construímos o desafio de operar nos limites das significações, uma vez que a linguagem não é compreendida como representação da realidade. Desta forma, abrem-se possibilidades de questionarmos o uso das TIC como algo dado, natural, para nos afastarmos da concepção teleológica do currículo e da educação.

\section{Tentativas de controle e a docência}

Essas tentativas de controle não se resumem apenas aos alunos, pois se estendem à prática docente. O professor aparece como figura central no projeto de introdução das TIC nas escolas, pois seria aquele responsável por levar tal conhecimento aos alunos. Para isso, deverá também ser preparado para lidar com as novas tecnologias tanto no período de sua formação inicial como ao longo de sua carreira no magistério. Mais uma vez trazemos Lyotard para pensar a relação entre o professor e o saber da era pós-industrial quando ele afirma que dentro de um sistema autorregulável (produção do saber como um modelo de máquina) o ato de educar estaria ligado à transmissão de técnicas para aplicação no mercado de trabalho. Nesse cenário, para Lyotard, o docente "não é mais competente que as redes de memória para transmitir o saber estabelecido” (2011, p. 95).

As discussões sobre políticas curriculares nos últimos anos têm sido "atravessadas por questionamentos em relação as tentativas de intensificação da construção de estratégias de controle de formas de representação" (MACEDO, 2016, p. 46). Tais tentativas de controle têm como justificativa o alcance de uma qualidade da educação que busca superar um determinado modelo de escola que discursos apontam como anacrônico. Assim, diferentes textos políticos, leis e normativas criam objetivos e metas educacionais a serem alcançados em médio e longo prazo a fim de superar uma educação em crise.

Quando a discussão sobre a introdução e o uso das TIC está em pauta podemos observar tal intento. A construção de um consenso em torno em torno de tal incorporação está relacionada a uma ideia de crise que marca a produção curricular no Brasil. A crise desempenharia, assim, o papel de inimigo exteriorizado e que então garantiria força de um "determinado discurso sobre o currículo e legitimar a exclusão de outras significações" (MACEDO, 2013, p. 445). Em relação às tecnologias, podemos apontar para o discurso 
hegemônico que coloca a inserção das TIC nas escolas como garantia do alcance de uma qualidade através da capacitação de alunos e professores.

Ao analisarmos tais projeções sobre o professor nos textos ao longo desta pesquisa, entendemos que é importante trabalharmos com os discursos sobre as TIC em sua relação com discentes e também docentes. É possível inferir, a partir das leituras dos textos, a repetição insistente da defesa da insuficiência da escola e dos professores de hoje para atender as necessidades de uma sociedade transformada pela tecnologia. Nesse sentido, as novas habilidades dos professores devem estar relacionadas ao uso dessas tecnologias e na possibilidade de transmitir aos alunos tais ferramentas para que eles possam utilizá-las no mercado de trabalho. Entendemos assim que é construído um consenso em torno da ideia de que sem as TIC não é possível ultrapassar as práticas tradicionais e alcançar o que chamam de sociedade do conhecimento através também do controle das práticas docentes. Interpretamos aqui um discurso marcado pela falta, de um vazio existente na educação que deve ser preenchido.

Mais uma vez vale ressaltar que entendemos tais discursos como pretensões de verdade e que a possibilidade de controle total é ilusória. Construímos este trabalho na contramão do entendimento de uma educação como um projeto universalista e essencialista (muitas vezes vinculado ao uso das TIC). Entendemos que o espaço vazio existente entre o que chamamos de universal e particular é o que possibilita a própria ação política (LACLAU, 1990). Esta fissura possibilita diferentes articulações políticas que têm como efeito as tentativas de representação dos sujeitos.

Nos textos políticos ibero-americanos a docência tem ganhado centralidade constituindo um discurso em que o trabalho do professor seria garantidor do êxito escolar dos alunos e consequentemente da melhoria da qualidade da educação (DIAS, 2016). Assim, a partir desses discursos, é defendido que sejam construídas políticas curriculares distintas sobre avaliação, formação, TIC, que possam garantir que os docentes atuem de maneira a possibilitar o êxito escolar dos discentes. No entanto, defendemos aqui que essas políticas têm como proposição o controle do trabalho e do que se defende como identidade docente.

As políticas curriculares em curso no contexto avaliado têm como orientação principal as tentativas de padronização dos sentidos do que seria uma educação de qualidade e do que seria um aluno bem-sucedido na escola. Dentro de um projeto moderno de sociedade, a escola seria a instituição responsável pela transmissão e propagação da cultura (PEREIRA, 2016) que possibilitaria a inserção dos sujeitos em uma comunidade que compartilharia os mesmos valores, conhecimentos e atitudes. Podemos inferir, a partir da análise dessa significação, que tal perspectiva de escola atende a um projeto moderno de educação de caráter universalizante que valoriza processos de padronização, desconsiderando as diferenças.

Macedo (2012) analisa diferentes perspectivas pedagógicas que buscam atribuir sentidos ao que seria a educação dividindo-as em dois grupos: a perspectiva técnica e a política. Nesta investigação, nos interessa discutir as aproximações que a autora faz entre esses dois grupos. Para ela, em ambas as teorias, 
ressoa a ideia de que a escola tem um compromisso primordial com a transmissão/recriação do conhecimento, que se vincula a um projeto social mais amplo, mas apenas como ferramenta. A escola é o lugar em que conhecimentos sociais, uma vez selecionados, são distribuídos, ensinados e aprendidos. Assim, o projeto de educação é um projeto de domínio, para uso mais ou menos crítico, de um conhecimento socialmente produzido - um conhecimento externo ao sujeito que, uma vez apropriado, pode fazer dele um trabalhador, um cidadão, um sujeito crítico. (MACEDO, 2012, p. 724)

Assim, para a autora, tanto as matrizes mais técnicas e liberais quanto as críticas tendem a aproximar o projeto de educação a "uma ideia de ensino - de conteúdo, de habilidades, de competências -, deixando de fora tudo o que não é passível de ser previamente determinado, e transformando a educação em mero reconhecimento, em inserção no já existente, em uma cultura já dada” (Idem, p. 723).

Dessa maneira, o projeto educacional hegemônico articula a escola com base em um fundamento de que existem valores e atitudes que devem ser compartilhados por todos. Tal projeto é determinado a priori, quando se define um modelo universal do que é o ensino e o aluno. Seria um projeto de formação identitária que desconsideraria aquilo que escapa, aquilo que não é controlável: a diferença. Como discutido anteriormente, a partir da matriz teóricometodológica na qual essa pesquisa se ampara, pensar a identidade como algo construído $a$ priori não é possível. De acordo com Laclau e Mouffe (2015), tal processo é uma tentativa de fixar determinados sentidos que, articulados discursivamente, produzem hegemonia em um movimento que bloqueia o surgimento de outros sentidos possíveis. Tal projeto pressupõe uma tentativa de controle do aluno e também do docente.

Os documentos curriculares produzidos pelos organismos internacionais para o contexto ibero-americano, alegando o pressuposto do alcance do que denominam qualidade da educação, propõem políticas sobre as TIC que têm como objetivo, em seus próprios termos, instrumentalizar a escola para formar o aluno do século XXI. No texto da UNESCO Declaração de Qingdao - "Leveraging ICT for Achieving Education 2030” (2015) ${ }^{3}$, a introdução das TIC nas escolas está vinculada à ideia de aprender a aprender e a aprendizagem ao longo da vida. Os discursos em defesa da aprendizagem/educação ao longo da vida têm sido propagados desde os anos 1970 (FAURE), pelos anos 1990 (DELORS) e atualmente com a Agenda 2030 (2016) em nome de

um projeto universal de formação, fortalecendo o vínculo com a formação continuada, a defesa de um currículo flexível e suas relações com a sociedade do conhecimento/aprendizagem e influenciando a formação e o trabalho docente. (DIAS; BORGES, 2018, p.335). 


\section{A qualidade como justificativa}

Como Laclau (1990), entendemos que toda objetividade é um mito cristalizado, sendo assim, o mito funcionaria como uma superfície cujos deslocamentos e as demandas sociais podem ser inscritos como discutido anteriormente. Através do mito, o "caos" estaria estabilizado, criando a ilusão de que as frustrações seriam combatidas e as reivindicações satisfeitas. Nesse caso, defendemos que as TIC estariam alcançando status de mito. Através das TIC se alcançaria uma "nova ordem" moderna que substituiria uma ordem tradicional (escola) em crise. Um "discurso que é aceito por diferentes setores, na medida em que implica em ordem, algo que é apresentado como uma alternativa crível a um deslocamento generalizado" (LACLAU, 1990, p. 66).

Sabemos que as estruturas discursivas não são fixas e estão sempre sofrendo diferentes tentativas de preenchimento através de novas articulações. Determinadas articulações e movimentos contingenciais levam a determinados sentidos e subjetivações, em determinados momentos um particular se universaliza. Diferentes demandas expressas nos diferentes discursos dos organismos internacionais, e aí estão presentes diferentes interesses de grupos distintos (mídia, professores, empresários, comunidades epistêmicas), se aproximam através do enfrentamento de um antagonismo em comum. Buscamos analisar nesta seção a possível construção de um antagonismo em torno do que denominamos escola tradicional.

Ao analisar os textos políticos selecionados, chama atenção a denominação, sobre a qual já falamos anteriormente, Sociedade do Conhecimento. Tal conceito é usado para definir o que se considera como a sociedade do século XXI, marcada pelo desenvolvimento tecnológico que transformou a sociedade e que têm impactos na produção do conhecimento e na produção de discursos que legitimam transformações na escola em favor dessa nova sociedade, na medida em que afirmam a necessidade da incorporação de novas competências e habilidades que respondam aos desafios.

Nesse sentido, a indicação de mudanças no sistema escolar da região ibero-americana, não deixa de lado as necessidades dessa sociedade do conhecimento. $\mathrm{O}$ que se defende nesse discurso é que a escola atual não conseguiu acompanhar as transformações da sociedade e que sua organização ainda é baseada em um ensino considerado tradicional, antiquado.

Por otro lado, existe un consenso en que la educación -concebida como fuente del desarrollo- debe ser distinta de aquella que nuestros países imaginaron durante gran parte del siglo xx. Este consenso, orientado por la necesidad de mejorar la calidad y equidad de la educación, "es amplio y nutre muchas de las reformas a los sistemas educacionales que casi todos los gobiernos emprenden hace más de una década. Si bien los contenidos y orientaciones de aquellas no son homogéneos entre los países, existe un sustrato común de coincidencia. Este sustrato incluye: replantearse el rol del Estado en la provisión de educación y conocimiento, desarrollar mecanismos de monitoreo y evaluación periódica de logros en el aprendizaje, reformular los mecanismos de financiamiento del sistema educacional, reformar los contenidos y prácticas pedagógicas en función de los nuevos soportes del conocimiento y los cambios en el mundo del trabajo, repensar 
el papel y la formación de los docentes, e introducir en las escuelas las nuevas tecnologías de información y conocimiento”. (SUNKEL, 2009, p. 29).

Tais preocupações se estendem às análises feitas aos sistemas escolares. Isto porque um dos grandes questionamentos do período diz respeito à insuficiência da educação tradicional em responder aos desafios postos por essas transformações. Em trabalho anterior (FARIAS; DIAS, 2013), havíamos observado uma preocupação crescente dos sujeitos com as transformações impostas pela “revolução informacional” não só no mercado de trabalho, mas também com as mudanças na própria concepção do que é conhecimento. As mudanças na escola devem estar alinhadas com as necessidades desse novo cenário, elas devem responder as demandas de uma aprendizagem ao longo da vida. Como afirma Carneiro; Toscano; Díaz (2009),

el conocimiento es el motor de las nuevas economías, su combustible es el aprendizaje. Por eso, el aprendizaje a lo largo de la vida surge como el mayor reto formativo presentado a las personas y a las organizaciones en el nuevo siglo.(p.56)

A defesa de uma aprendizagem ao longo da vida, como lembram Dias e Borges (2018) vincula-se ao discurso da sociedade do conhecimento/informação presente nos textos políticos analisados que propagam as TIC para responder as demandas sociais da educação tendo como foco alcançar as mudanças na escola que têm como propósito superar o que vem sendo significado como uma educação tradicional.

A questão da aprendizagem ganha importância nesses documentos na medida em que afirmam que a incorporação das TIC seria fundamental para a conquista de uma escola que de fato preparasse o aluno para a aprendizagem ao longo da vida (FARIAS, 2019).

A crescente incorporação das TIC, bem como seu avanço no campo educacional, não somente possibilitam diferentes formas de aprender, mas também têm diversificado os contextos e o que se entende hoje como aprendizagem. Um uso adequado dessa informação pode nos oferecer novas formas de analisar e promover as aprendizagens, a partir de perspectivas que vão além dos campos dos conhecimentos tradicionais e das metodologias tipicamente de avaliação e intervenção. Porém, é necessário desenvolver capacidades profissionais multidisciplinares e esforços interinstitucionais, a fim de integrar, processar e analisar essas informações, tanto para o desenvolvimento de novos conhecimentos, como para a tomada de decisões de políticas e a elaboração de dispositivos de melhoria. (COBO, 2016, pp. 52 e 53).

Só a incorporação das tecnologias não seria o suficiente para que se consiga a superação do que é considerado uma educação tradicional. Até uns anos atrás a inserção das TIC nas escolas estava relacionada apenas ao acesso às ferramentas informacionais, mas as análises mais recentes dão suporte para o discurso de que isso não seria mais o suficiente. 
Um dos principais objetivos das políticas de TIC para as escolas consiste em fornecer às novas gerações as habilidades digitais que permitirão que elas se desenvolvam com sucesso no século XXI (...) Para o setor educacional, isso apresenta o desafio de formar pessoas que não possuam apenas uma formação sólida em habilidades tradicionais (leitura, escrita e matemática), mas que também sejam capazes de resolver problemas não rotineiros e manejar informações complexas, muitas vezes apresentadas em ambiente digital (LEVY; MURNANE, 2007). Assim, atualmente existe um crescente consenso de que os estudantes deveriam desenvolver habilidades de ordem superior, necessárias para resolver problemas de gestão de informações e da comunicação, tais como pesquisar, avaliar, sintetizar, analisar e representar informações, no ambiente digital; bem como ter a capacidade de utilizar as ferramentas digitais para compartilhar e colaborar com outros. (JARA, 2016, p.73).

Assim, as TIC devem ser utilizadas para ajudar no desenvolvimento de habilidades distintas, que responderiam as demandas da sociedade tecnológica do século XXI.

Há alguns anos, a atenção internacional está concentrada em avaliar o desenvolvimento desse tipo de habilidades. Há 20 anos, entendia-se que as habilidades digitais se referiam basicamente à capacidade de operar os computadores e seus diferentes programas. Posteriormente, surgiu um conceito mais amplo de alfabetização digital, que transcende as habilidades de manejo técnico das TIC. Esse conceito surgiu de enfoques vinculados às chamadas habilidades do século XXI, que apresentam evidências de que o mercado de trabalho não valoriza as habilidades técnicas por si só, mas também habilidades cognitivas de ordem superior no contexto do uso das TIC. Essas habilidades representam a base da capacidade que se deseja desenvolver nos estudantes para que aprendam por si mesmos, de maneira autônoma e ao longo de sua vida; e da capacidade de participar, incorporar novos conhecimentos e inovar nos processos produtivos e sociais nos quais lhes participarão. (Ibid).

Cabe aqui discutirmos algumas das afirmações do trecho acima. Primeiramente, é importante nos atentarmos para a questão de que o ensino dessas novas habilidades, chamadas superiores pelo autor, é defendido para atender uma demanda do mercado de trabalho. O mundo em constante transformação requer do novo trabalhador condições de adaptabilidade às mudanças e às novas formas de trabalho. $\mathrm{O}$ que nos leva a segunda afirmação, a de que se deseja desenvolver tais habilidades nos estudantes "para que aprendam por si mesmos, de maneira autônoma e ao longo de sua vida”, discurso que aparece como consenso nos documentos analisados. É importante destacar que a aprendizagem ao longo da vida é entendida como uma forma de auxiliar o sujeito na sua inserção nos processos produtivos e sociais do mundo atual.

Como analisado no excerto anterior, a qualidade atribuída às TIC tem como potencial, não apenas o conhecimento na utilização dos artefatos que envolvem tais tecnologias para explorar experiências de ensino-aprendizagem como também o de produzir sujeitos com 
capacidades de pesquisar, analisar, avaliar, solucionar problemas e tomar decisões. Nessas demandas, os discursos dos textos analisados atribuem um papel central às TIC como operadora de mudanças na formação do educando e do cidadão.

Tal entendimento está estreitamente vinculado com a perspectiva que defende que a formação de qualidade dos alunos tem ligação direta com a capacidade de crescimento e desenvolvimento de um país associando-se com os aspectos político-econômicos, destacadamente do setor produtivo. Nesse sentido, preparar o indivíduo para viver e trabalhar na sociedade do conhecimento requer uma série de habilidades e competências, que quando bem desenvolvidas agregam valor a uma nação.

Alternativamente, o crescimento econômico de um país pode ocorrer com os aumentos no valor econômico gerado por seus cidadãos. Os modelos econômicos de "novo crescimento" enfatizam a importância de novos conhecimentos, inovação e desenvolvimento da capacidade humana como fontes do crescimento econômico sustentável. É por intermédio da educação e do desenvolvimento da capacidade humana que as pessoas não só agregam valor à economia, mas também contribuem com o patrimônio cultural, participam do discurso social, melhoram a saúde da família e da comunidade, conservam o ambiente natural e aumentam sua própria organização e capacidade de continuar a se desenvolver e a contribuir, criando um círculo virtuoso de desenvolvimento pessoal e participação. (UNESCO, 2008, p. 7-8).

Assim, caberia à escola o papel de preparar seus alunos não apenas para o uso das ferramentas tecnológicas, mas ajudar na formação de alunos que possam produzir conhecimento. Em nossa análise, observamos nos documentos selecionados a defesa do sentido de um conhecimento diretamente relacionado ao tecnológico, que favoreça o desenvolvimento da economia dos países, pois essa seria uma característica fundamental para dar competitividade e protagonismo aos mesmos. Como exemplo, podemos citar o trecho a seguir retirado do documento Padrões de Competência em TIC para Professores:

O projeto ICT-CST pretende criar um vínculo entre a reforma do ensino e o crescimento econômico e desenvolvimento social, capaz de melhorar a qualidade da educação, reduzir a pobreza e a desigualdade, aumentar o padrão de vida e preparar os cidadãos de um país para os desafios do século XXI. Os padrões se baseiam em três abordagens da reforma do ensino que correspondem a perspectivas alternativas, às vezes sobrepostas, para melhorar a força de trabalho de um país e incentivar o crescimento econômico (...)

Juntas, elas apresentam uma trajetória de desenvolvimento em que a reforma do ensino apoia formas cada vez mais complexas de desenvolver a economia e a sociedade de um país: de uma maior compreensão sobre a tecnologia, passando pelo estímulo a uma força de trabalho de alto desempenho até a criação de condições para uma economia do conhecimento e uma sociedade da informação. Com essas abordagens, os alunos e, por fim, os cidadãos e a força de trabalho, 
adquirem habilidades cada vez mais complexas que são necessárias para apoiar o crescimento econômico e melhorar os padrões de vida. (UNESCO, 2008c, p. 6).

Mais uma vez, podemos identificar o discurso que aponta para as transformações da sociedade do conhecimento, nesse caso, em um viés mais economicista. Vinculada a tal discurso, observamos a demanda pela mudança nas escolas para que estas alcancem os padrões necessários para preparar alunos capazes de trabalharem e viverem em uma sociedade de informação.

O objetivo político é aumentar a participação cívica, a criatividade cultural e a produtividade econômica; desenvolvendo alunos, cidadãos e uma força de trabalho permanentemente envolvida com a e se beneficiando da: criação de conhecimento, inovação e participação na sociedade de aprendizagem. As implicações dessa abordagem para as mudanças no currículo e em outros componentes do sistema educacional são significativas, pois, nessa modalidade, o currículo ultrapassa as fronteiras das disciplinas escolares, com a inclusão das habilidades provenientes das demandas do século XXI em direção a um novo conhecimento que envolve o aprendizado por toda a vida - a habilidade de colaborar, comunicar, criar, inovar e pensar de forma crítica. (UNESCO, 2008b, p. 11).

Defendemos aqui que a ideia de conhecimento que aparece com destaque nos discursos analisados relaciona este último ao contexto produtivo. Conhecimento é aquilo que deve ser transmitido na escola de modo a ser aplicado no que eles chamam de "mundo real” (FARIAS, 2019). Destacamos aqui alguns trechos que defendem a ideia de uma separação entre a escola e o mundo real.

Os professores devem ser capazes de:

- Descrever como o aprendizado colaborativo, com base em projeto, pode, junto com as TIC, ajudar o aluno no seu pensamento e interação social, à medida que eles entendam os conceitos-chave, processos e habilidades na matéria, usando-os para solucionar problemas do mundo real.

- Identificar ou elaborar problemas complexos do mundo real e estruturá-los de forma a incorporar os principais conceitos da matéria e servir como base para os projetos do aluno.

- Elaborar materiais online que apoiem o melhor entendimento dos alunos sobre os principais conceitos e sua aplicação no mundo real. (UNESCO, 2008c, p. 1213).

Para que se alcance esse desenvolvimento e na tentativa de transformar países em desenvolvimento em países mais competitivos o discurso presente no documento aponta para a necessidade de essas habilidades estarem presentes nas escolas. Dentre as habilidades expostas para atingir tais finalidades estão: 
- Ajudar os alunos a adquirirem habilidades em TIC no contexto de seus cursos; - Utilizar as TIC para avaliar até que ponto os alunos apreenderam o conhecimento da disciplina escolar;

- Descrever como o ensino didático e as TIC podem ser usadas para apoiar a aquisição de conhecimento, por parte dos alunos;

- Usar programa de apresentação e recursos digitais como apoio ao ensino;

- Descrever e demonstrar o uso de equipamentos tecnológicos comuns;

- Descrever e demonstrar as tarefas básicas e o uso de processadores de texto, como composição de texto, edição de texto, formatação de texto e impressão;

- Descrever a finalidade e a função básica do programa de gráficos e usar um pacote com esse tipo de programa para criar uma exibição gráfica simples;

-. Descrever a internet e a World Wide Web, elaborar seus usos e descrever como funciona um navegador, usando uma URL para acessar um sítio;

- Usar uma ferramenta de busca para fazer uma pesquisa boleana por palavrachave;

- Criar uma conta de e-mail e usá-la para uma série contínua de troca de mensagens;

- Utilizar o programa de manutenção de arquivos em rede para registrar presença, apresentar as notas e manter os registros do aluno;

- Usar tecnologias comuns de comunicação e colaboração, tais como mensagens de texto e videoconferência. (UNESCO, 2008c, p. 09-10).

É importante pontuarmos que nos textos políticos analisados estão discursos que possuem outros entendimentos sobre essas novas habilidades. São entendimentos que buscam universalizar sentidos sobre a ideia de democratização, a necessidade de formar cidadãos que possam utilizar as tecnologias de maneira mais crítica e a necessidade de se utilizar essas habilidades em defesa dos Direitos Humanos e da ética, por exemplo.

Os resultados dessa competência devem incluir as seguintes habilidades dos professores: - identificar, descrever e avaliar as funções de utilidade pública das mídias e de outros provedores de informação nas sociedades democráticas; demonstrar uma compreensão de conceitos centrais, como liberdade de expressão, acesso à informação e direitos fundamentais contidos no Artigo 19 da Declaração Universal dos Direitos Humanos (DUDH); - interpretar e descrever as relações entre a alfabetização midiática e informacional, a cidadania e a democracia; descrever o pluralismo nas mídias, as mídias e outros provedores de informação como plataformas para o diálogo intercultural, e saber por que essas questões são importantes; - caracterizar a independência editorial; - explicar o jornalismo como uma disciplina de verificação dentro de um mandato de serviço público; descrever a ética midiática e informacional e estar em condições de identificar situações nas quais essa ética foi infringida. (UNESCO, 2013, p. 27). 


\section{Considerações finais}

Identificamos aqui deslizamentos nos sentidos sobre essas habilidades necessárias para a educação com as TIC no século XXI. Enquanto identificamos um discurso dominante de que as habilidades são necessárias para a preparação do aluno para o mercado de trabalho, a partir de um viés mais economicista, é possível encontrar o entendimento dessas habilidades relacionadas a outras demandas. O que esses sentidos têm em comum é algo que eles pretendem eliminar ou superar, o ensino tradicional. Esse entendimento não é questionado, seria preciso transformar as escolas a partir do uso das TIC para que se alcance a sociedade do conhecimento e a qualidade da educação. "São processos de identificação dos sujeitos participantes das lutas políticas articulatórias” (LACLAU, 1990, p. 211) contra um inimigo comum. Contudo, o que consiste esse ensino tradicional contra o qual as TIC pretendem se contrapor? O que existe de inovador no discurso que pretende associar as TIC a uma nova forma de aprendizagem comum a diferentes alunos e escolas e novos professores que atendam às expectativas de uma sociedade do conhecimento cada vez mais atenta às demandas de formação para o setor produtivo?

\section{Notas}

1. Este artigo deriva da tese de doutorado de Lívia Moura Cardoso Bastos de Farias Políticas Curriculares e as TIC no contexto Ibero-americano - tentativas de superação de uma educação tradicional, defendida em 2019 no Programa de Pós-Graduação em Educação da UERJ, orientada por Rosanne Evangelista Dias, Procientista da UERJ e Jovem Cientista do Nosso Estado - FAPERJ.

2. Para maiores informações sobre o uso das TIC pelo Exército Zapatista de Libertação Nacional indico a leitura do texto “A globalização e os novos movimentos sociais: lições para a Teoria e a Pedagogia Críticas, de Douglas Kellner, como parte da coletânea organizada por Nicholas C. Burbules e Carlos Alberto Torres “Globalização e educação: perspectivas críticas”, publicado pela Artmed em 2004.

3. QINGDAO DECLARATION foi um documento produzido como resultado da "INTERNATIONAL CONFERENCE ON ICT AND POST-2015 EDUCATION Seize digital opportunities, lead education transformation” que ocorreu entre os dias 23-25 de maio de 2015, em Qingdao, República Popular da China. O propósito da conferência foi a discussão de como explorar o potencial das TIC para que se possa universalizar o ensino em todas as regiões e atingir uma educação de qualidade. A conferência teve participação de Ministros da Educação de diferentes países, representantes de organizações sociais, organizações de professores, agências da ONU, membros da academia e representantes do setor privado. Informações retiradas do site da http://www.unesco.org/new/fileadmin/MULTIMEDIA/HQ/ED/pdf/Qingdao_Declaration.pdf Acesso em outubro de 2018.

\section{Referências Bibliográficas}

COBO, Cristobal. Plano Ceibal: novas tecnologias, pedagogias, formas de ensinar, aprender e avaliar. In: FUNDAÇÃO TELEFÔNICA; UNESCO. Experiências Avaliativas de Tecnologias Digitais na Educação. São Paulo: 2016.

CUNHA, Erika Virgilio Rodrigues da. Conexão entre Currículo e Avaliação como Ficção de Controle de identidade. In: FRANGELLA, Rita de Cassia Prazeres (org.). Currículo, formação e avaliação: redes de pesquisas em negociação. Curitiba: CRV, 2016.p.111-128. 
DIAS, Rosanne, BORGES, Veronica. Por uma educação/aprendizagem ao longo da vida: traços discursivos nas políticas curriculares. In: LOPES, Alice, OLIVEIRA, Anna Luiza, OLIVEIRA, Gustavo Gilson (org.). A teoria do discurso na pesquisa em educação. Recife: Editora da UFPE, 2018, p.333-360.

DIAS, Rosanne Evangelista. Políticas de currículo e avaliação para a docência no espaço Iberoamericano. Práxis Educativa (UEPG. Online), v. 11, p. 590-604, 2016.

FARIAS, Lívia Moura Cardoso Bastos de. Políticas Curriculares e as TIC no contexto Ibero-americano tentativas de superação de uma educação tradicional. Rio de Janeiro, 2019. 177 f. Tese (Doutorado em Educação). Faculdade de Educação. Universidade do Estado do Rio de Janeiro, 2019

FARIAS, Lívia Cardoso; DIAS, Rosanne Evangelista. Discursos sobre o uso das TIC na educação em documentos ibero-americanos. Linhas (Florianópolis. Online), v. 14, p.83-104, 2013.

JARA, Ignacio. Rede Enlaces, Ministério da Educação do Chile. In: FUNDAÇÃO TELEFÔNICA; UNESCO. Experiências Avaliativas de Tecnologias Digitais na Educação. São Paulo: 2016.

KELLNER, Douglas. A globalização e os novos movimentos sociais: lições para a teoria e a pedagogia críticas. In: BURBULES, Nicholas C., TORRES, Carlos Alberto (org.). Globalização e educação: perspectivas críticas. Porto Alegre: Artmed Editora, 2004. p.195-208.

LACLAU, Ernesto. New reflections on the resolution of our time. Londres: Verso, 1990.

LACLAU, Ernesto; MOUFFE, Chantal. Hegemonia e Estratégia Socialista: por uma poítica democrática radical. São Paulo, Intermeios, 2015.

LOPES, Alice Casimiro. Teorias pós-críticas, política e currículo. Educação, Sociedade \& Culturas, v. 39, p. 7-23, 2013.

LOPES, Alice Casimiro; BORGES, Veronica. Formação docente, um projeto impossível. Cadernos de Pesquisa (Fundação Carlos Chagas), v. 45, p. 486-507, 2015.

LYOTARD, Jean-François. A Condição Pós-Moderna. Rio de Janeiro: Editora José Olympio, 2011.

MACEDO, Elizabeth. Currículo e conhecimento: aproximações entre educação e ensino. Cadernos de Pesquisa (Fundação Carlos Chagas),. v.42 n.147, set./dez. 2012, pp.716-737.

MACEDO, Elizabeth. A noção de crise e a legitimação de discursos curriculares. Currículo sem Fronteiras, v. 13, n. 3, p. 436-450, set./dez. 2013.

MACEDO, Elizabeth. Base nacional curricular comum: a falsa oposição entre conhecimento para fazer algo e conhecimento em si. Educação em revista [online]. vol.32, n.2, pp.45-68, 2016.

PEREIRA, Talita. Conhecimento Escolar e Trabalho Docente. In: FRANGELLA, Rita de Cassia Prazeres (org.), Currículo, formação e avaliação: redes de pesquisas em negociação. Curitiba: CRV, 2016.

RECUEIRO, Raquel. As redes sociais na internet. Porto Alegre: Sulina, 2009.

SUNKEL, Guilhermo. Las TIC en la educación de América Latina: visión panorámica. In: CARNEIRO, Roberto; TOSCANO, Juan Carlos; DÍAZ, Tamara. Los desafíos de las TIC para el cambio educativo. Espanha: Organización de Estados Iberoamericanos para la Educación, la Ciencia y la Cultura com Fundacion Santillana, 2009.

\section{Textos políticos analisados}

CARNEIRO, Roberto; TOSCANO, Juan Carlos; DÍAZ, Tamara. Los desafíos de las TIC para el cambio educativo. Espanha: Organización de Estados Iberoamericanos para la Educación, la Ciencia y la Cultura com Fundacion Santillana, 2009.

OEI. Metas Educativas 2021-La Educación que Queremos para la Generación de los Bicentenarios. 2010a.

OEI. Metas Educativas 2021 - Síntese em Português. 2010b. 
OEI; TELEFONICA. A integração das TIC na escola. Indicadores qualitativos e metodologia de pesquisa. 2013

OEI. Miradas sobre la educacion. Espanha: Organización de Estados Iberoamericanos para la Educación, la Ciencia y la Cultura. com Fundación Santillana, 2014.

UNESCO. Padrões de Competência em TIC para professores - Marco Político, 2008.

BASTOS, M. I. O impacto das TICs na educação: o desenvolvimento de competências em TIC para a educação na formação de docentes na América Latina. Brasília: MEC em parceria com a UNESCO, 2010.

FUNDAÇÃO TELEFÔNICA; UNESCO. Experiências Avaliativas de Tecnologias Digitais na Educação. São Paulo: 2016.

\section{Correspondência}

Lívia Moura Cardoso Bastos de Farias: Graduada em História pela UFRJ, Mestre em Educação pela mesma universidade. Doutora em Educação pela UERJ. Professora de História na Escola Britânica.

E-mail: livfarias@hotmail.com

Rosanne Evangelista Dias: Professora Adjunta da Faculdade de Educação e do Programa de Educação em Educação da UERJ. Líder do Grupesq CNPq Políticas de Currículo e Docência. Doutora em Educação pela UERJ. Procientista da UERJ e Jovem Cientista do Nosso Estado - Faperj.

E-mail: rosanne_dias@uol.com

Texto publicado em Currículo sem Fronteiras com autorização das autoras 